\title{
Desmídias (Zygnematophyceae) de hábito filamentoso da região do Vale do Paranã (Goiás, Brasil)
}

\author{
Filamentous desmids (Zygnematophyceae) from Valley of Paranã (Goiás, Brazil)
}

\author{
Ina de Souza Nogueira ${ }^{1,2}$, Vanessa Araújo Jorge ${ }^{1,2}$, Lorena Lemes Martins Abrantes ${ }^{1,2}$ \\ \& Maria Tereza Morais Pereira Souza Lobo ${ }^{1,2}$
}

\begin{abstract}
Resumo
A região do Vale do Paranã faz parte do bioma Cerrado e da bacia Tocantins-Araguaia, no estado de Goiás. O estudo constitui o primeiro trabalho para região e visa apresentar o inventário de desmídias de hábito filamentoso. Foram coletadas 102 amostras nos períodos de seca e chuva de 2003 através de diferentes métodos. As algas foram analisadas, microfotografadas e identificadas. A análise qualitativa resultou em 17 táxons. Hyalotheca dissiliens var. dissiliens f. dissiliens foi mais frequente no período chuvoso, enquanto Spondylosium panduriforme var. panduriforme f. panduriforme e Spondylosium panduriforme var. limneticum no período seco. Os alagados de várzea foram os ambientes mais propícios ao desenvolvimento de desmídias, sendo $71 \%$ dos táxons, exclusivos deste tipo de ambiente. $\mathrm{O}$ ambiente mais rico durante todo período estudado foi um alagado de Formosa com $94,1 \%$ dos táxons de desmídias filamentosas. Oito novas citações foram registradas para o estado de Goiás.
\end{abstract}

Palavras-chave: Desmidiales, bioma Cerrado, taxonomia, Tocantins-Araguaia.

\begin{abstract}
The region of the Paranã Valley is part of the Cerrado biome and Tocantins-Araguaia basin (Goiás state, Brazil). The study constitutes the first work for the region and aims to present the inventory of filamentous desmid forms. 102 samples were coleted in the rainy and dry seasons though different methods. The algae had been analyzed and microphotographed and identified. The qualitative analysis resulted in 17 taxa. Hyalotheca dissiliens var. dissiliens f. dissiliens was most frequent in the rainy while in the dry period Spondylosium panduriforme var. panduriforme f. panduriforme and Spondylosium panduriforme var. limneticum. The floodplain environment had been most propitious for filamentous desmid and $71 \%$ of taxa were exclusive of this environment. The sampling station of Formosa presented the most specific richness with $94,1 \%$ of taxa filamentous desmid. There were registered eight new taxa to the state of Goiás.
\end{abstract}

Key words: Desmidiales, Cerrado biome, taxonomy, Tocantins-Araguaia.

\section{Introdução}

A serra e o vale do Rio Paranã, estão inseridos no bioma Cerrado e situam-se a nordeste do estado de Goiás. Trata-se de uma área que pode ser considerada como um dos hotspots mundiais de biodiversidade (Myers et al. 2000), em decorrência da expansão da agricultura e exploração dos recursos naturais.

Nesta região encontra-se atividade intensa de desmatamento, com a retirada de madeiras nobres de áreas de Floresta Estacional Decidual (mata seca). Destaca-se ainda a extração de rocha calcária contribuindo para a minimização da vegetação que ocorre sobre estes afloramentos (Scariot et al. 2003).

O Ministério do Meio Ambiente classificou a região da serra e vale do Rio Paranã em área de elevada biodiversidade considerando de fundamental importância o inventário da biota aquática para se conhecer a diversidade da referida localidade (Brasil 2004, 2007).

Segundo Martins-Silva et al. (2008) a serra e vale do Rio Paranã pode ser caracterizada pela presença de corpos aquáticos variados. Destacam-se córregos de pequeno porte e de forte correnteza na

\footnotetext{
${ }^{1}$ Universidade Federal de Goiás, Inst. Ciências Biológicas I, Depto. Biologia Geral, sl. 206, Alameda Palmeiras qd. A8, Campus II, C.P. 131, 74001-970, Goiânia, GO, Brasil.

22Autoras para correspondência: ina.nogueira@gmail.com; vanessajorge@hotmail.com; lorenaueg@yahoo.com.br; mariatereza_lobo@yahoo.com.br
} 
região serrana (Ribeirão Itiquira, Córrego Palmeira, Riacho dos Porcos, Córrego Jataí, Córrego Água Fria, Córrego São Pedro, Ribeirão Extrema, Ribeirão Faria, Córrego Ribeirão, Rio São Bartolomeu, Córrego Forquilha, Córrego Morcego). Nas localidades de vale ocorrem rios de volume hídrico maior com correnteza mais lenta assim como a presença de lagoas temporárias (Córrego Cangalho, Rio Macacos, Rio Correntes, Rio Água Quente, Rio São Mateus).

De um modo geral, a família Desmidiaceae apresenta riqueza taxonômica elevada, sendo composta por 36 gêneros, dos quais 11 são de hábito filamentoso. Este grupo de algas é caracterizado pela presença de pseudofilamentos retos ou torcidos, células com formas cilíndricas, globosas, elípticas, podendo ser decoradas com estrias, pontuações, grânulos ou espinhos. A forma do plastídio (lâmina, estrelado ou fita) constitui caráter taxonômico para a distinção de gêneros (Reviers 2003; Bicudo \& Menezes 2006; Oliveira et al. 2010).

O estado de Goiás, até o ano de 2016, conta com 39 trabalhos referentes a algas, sendo 08 destes com citações de desmídias de hábito filamentoso (Prescott 1957; Förster 1964; Campos \& MacedoSaidah 1990; Dias \& Sophia 1994; Brandão \& Kravchenko 1997; Silva et al. 2001; Felisberto \& Rodrigues 2002; Oliveira et al. 2011).

A região do vale do Paranã é uma das mais incipientes de informação sobre a biodiversidade aquática, e não apresenta qualquer registro sobre algas em literatura até o momento. Este trabalho visa, portanto, inventariar as desmídias de hábito filamentoso da região do vale do Paranã durante o período de chuva e seca de 2003, ampliando, assim, o conhecimento da biodiversidade deste grupo de algas verdes em território nacional.

\section{Material e Métodos}

A região do vale do Paranã é composta por inúmeros recursos hídricos lóticos e ambientes de várzeas que formam os lênticos. Esta região faz parte do bioma Cerrado que ocupa uma área de aproximadamente 5.940.382 ha (1309'57' -

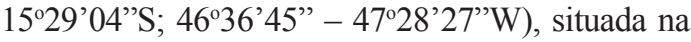
bacia Tocantins-Araguaia.

As estações de coleta selecionadas estão localizadas nos municípios de Nova Roma, Iaciara, São João da Aliança, Flores de Goiás e Formosa (Tab. 1 e Fig. 1). Durante o período de chuva e seca foram amostradas 28 e 31 estações, respectivamente, tendo sido coletadas 45 amostras em março (chuva) e 57 amostras em setembro (seca) de 2003. Buscou-se uma amostragem de abrangência espacial (ambientes lênticos e lóticos em toda área estudada - Tab. 2).

As coletas foram efetuadas por meio de processo seletivo (rede de plâncton de $25 \mu \mathrm{m}$ de abertura de malha) e processos não seletivos (recolhimento de aproximadamente $500 \mathrm{ml}$ de água do local, de massas algais e de diferentes substratos naturais disponíveis), sendo acondicionado em frasco de vidro de $100 \mathrm{~mL}$, com tampa de pressão de polietileno.

As amostras foram fixadas no momento da coleta com solução de Transeau (Bicudo \& Menezes

Tabela 1 - Localização geográfica das estações de amostragem em que se observaram a presença de desmídias filamentosas com indicativo do número de coletor.

Table 1-Geographical location of sampling stations where there is the presence of filamentous desmids with indicative of the collector number.

\begin{tabular}{|c|c|c|c|c|}
\hline Município & Local & Coordenadas Geográficas & $\begin{array}{c}\begin{array}{c}\text { Chuva } \\
\text { Março 2003 }\end{array} \\
\text { N.C }\end{array}$ & $\begin{array}{c}\text { Seca } \\
\text { Setembro } 2003 \\
\text { N.C }\end{array}$ \\
\hline Iaciara & Brejo $2 \mathrm{~km}$ antes do rio São Mateus & $13^{\circ} 49^{\prime} 36,2^{\prime \prime} \mathrm{S}-46^{\circ} 38^{\prime} 55,7^{\prime \prime} \mathrm{W}$ & $\begin{array}{l}805 \\
808\end{array}$ & \\
\hline Formosa & Rio Jataí (próximo ao bar do Jacaré) & $15^{\circ} 06^{\prime} 58,3 ” \mathrm{~S}-47^{\circ} 27^{\prime} 42,8^{\prime \prime} \mathrm{W}$ & 825 & \\
\hline Formosa & $\begin{array}{l}\text { Brejo entre os rios Jataí e dos Porcos, } \\
\text { sentido Itiquira }\end{array}$ & $15^{\circ} 09^{\prime} 32,1^{\prime \prime} \mathrm{S}-47^{\circ} 28^{\prime} 04,7^{\prime \prime} \mathrm{W}$ & 827 & 1095 \\
\hline Formosa & Rio Itiquira & $15^{\circ} 19^{\prime} 26,7^{\prime \prime} \mathrm{S}-47^{\circ} 25^{\prime} 27,3^{\prime \prime} \mathrm{W}$ & 829 & \\
\hline Flores de Goiás & $\begin{array}{l}\text { Alagado tipo várzea (Brejo) a 10,4 km } \\
\text { antes da cidade de Flores }\end{array}$ & $14^{\circ} 32^{\prime} 41,5 ” \mathrm{~S}-47^{\circ} 01^{\prime} 47,3$ ” W & 834 & \\
\hline São João da Aliança & Córrego Ribeirão & $14^{\circ} 30^{\prime} 43,2^{\prime \prime} \mathrm{S}-47^{\circ} 16^{\prime} 43,9^{\prime \prime} \mathrm{W}$ & & 1085 \\
\hline
\end{tabular}

N.C: Número de coletor.

N.C: Number of the collector. 
Tabela 2 - Indicativo do número de coletor das amostras com Zygnematophyceae de hábito filamentoso, respectivos ambientes e comunidades amostradas.

Table 2-Indicative of the samples Zygnematophyceae filamentous habit with collector number, their environments and communities sampled.

\begin{tabular}{llll}
\hline Número de Coletor & & Ambiente e Comunidade \\
805 & & Lêntico - Plâncton \\
808 & Lêntico - Espremido de Macrófita \\
825 & Lótico - Plâncton \\
827 & Lêntico - Espremido de Macrófita \\
829 & Lótico - Plâncton \\
834 & Lêntico - Metafiton \\
1085 & Lótico - Metafiton \\
1095 & Lêntico - Plâncton \\
\hline
\end{tabular}

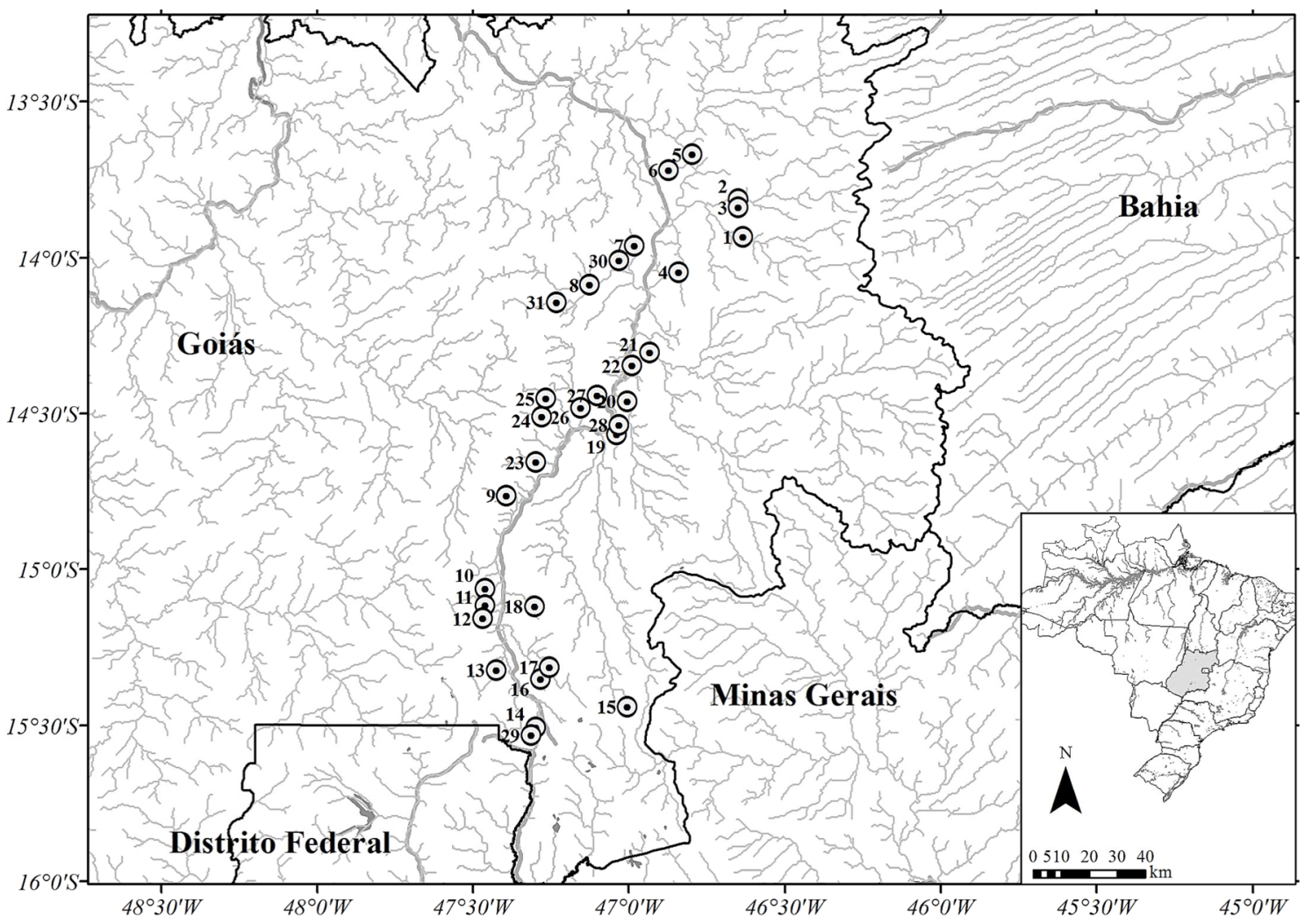

Figura 1 - Localização geográfica da região do vale do Paranã com as respectivas estações amostrais (Estação 1-4: Município de Iaciara; Estação 5-8 e 30: Nova Roma; Estação 9, 23-25 e 31: São João da Aliança; Estação 10-18 e 29: Formosa; Estação 19-22 e 27-28: Flores de Goiás; Estação 26: Divisa dos municípios de São João da Aliança e Flores de Goiás).

Figure 1 - Geographic localization of the Valley of Paranã with respective sampling stations (Station 1-4: City of Iaciara; Station 5-8 and 30: Nova Roma; Station 9, 23-25 and 31: São João da Aliança; Station 10-18 and 29: Formosa; Station 19-22 and 27-28: Flores de Goiás; Station 26: Between city of São João da Aliança and Flores de Goiás). 
2006) e posteriormente incorporadas ao Herbário da UFG com réplica para o Herbário UNB. As amostras de água bruta (processos não seletivos) foram sedimentadas no próprio frasco, retirados o sobrenadante e transferidas para os mesmos tipos de frascos. O material fixado foi analisado com base nas características morfológicas e morfométricas. Para análise qualitativa foi utilizado microscópio óptico Zeiss Axioscop 40. Sempre que possível, as características morfológicas (vegetativas e reprodutivas) dos táxons foram microfotografadas, ilustradas e medidas.

O sistema de classificação adotado para as classes taxonômicas foi o de Hoek et al. (1995). As algas analisadas foram identificadas de acordo com a seguinte literatura: Prescott (1957); Förster (1964); Prescott et al. (1982); Dias \& Sophia (1994); Croasdale et al. (1994); Lezenweger (1997). Os táxons registrados neste trabalho que constituem novas citações para o estado de Goiás apresentam descrição, ilustração, distribuição geográfica e registro de herbário. Os outros táxons já devidamente descritos e/ou ilustrados para o estado de Goiás apresentam apenas os valores métricos das células e outras informações.

\section{Resultados e discussão}

Das 102 amostras analisadas, oito apresentaram desmídias de hábito filamentoso (Tab. 3). Foram identificados 17 táxons, sendo cinco espécies, nove variedades (três típicas e seis não típicas) e três formas taxonômicas típicas, que estão descritas e ilustradas a seguir:

\section{Zygnematophyceae \\ Desmidiales \\ Desmidiaceae}

\section{Chave de identificação para os táxons identificados:}

1a. Pseudofilamentos com células unidas através de processos mucilaginosos ou grânulos

2a. Células unindo-se por grânulos, ausência de espinhos laterais..........Teilingia excavata var. westii

2b. Células unindo-se por processos mucilaginosos, presença de espinhos laterais

3a. Espinhos laterais longos, acima de $7 \mu \mathrm{m}$, aproximadamente do tamanho dos processos ........ Onychonema laeve var. laeve

3b. Espinhos laterais pequenos, menor que $3 \mu \mathrm{m}$, menor que os processos

4a. Semicélula oblonga, margem lateral convexa prolongada em espinhos curtos e paralelos, processos acima de $7 \mu \mathrm{m}$ Onychonema laeve var. micracanthum

4b. Semicélula oblongo-eliptica, margem lateral convergente prolongada em espinhos longos convergentes, processos menores que $6 \mu \mathrm{m}$

Onychonema laeve var. latum

1b. Pseudofilamentos com células unidas por parte ou por toda superfície da margem apical

5a. Células com formação de prega na parede celular durante a divisão vegetativa

6a. Parede celular lisa,

7a. Semicélula retangulares, margem lateral ondulada

Desmidium baileyi var. baileyi f. baileyi

7b. Semicélula piramidal, margem lateral...............Desmidium graciliceps var. groenbladii

6b. Parede celular com estrias longitudinais na parte superior da semicélula

Bambusina brebissonii var. brebissonii

6c. Parede celular com grânulos tênues, margem lateral convexa e convergente em direção ao ápice .....

Desmidium bicristatosporum

5b. Células sem formação de prega na parede celular durante a divisão vegetativa

8a. Seno mediano bem marcado

9a. Vista apical circular, margem lateral arredondada

10a. Células com menos de $20 \mu \mathrm{m}$ de comprimento.

Spondylosium panduriforme var. panduriforme f. panduriforme

10b. Células com mais de $30 \mu \mathrm{m}$ de comprimento.

Spondylosium panduriforme var. limneticum

9b. Vista apical elíptica a subretangular Spondylosium rectangulare

9c. Vista apical elíptica Spondylosium ellipticum 
9d. Vista apical quadrangular, margem lateral reta e pouco intumescida na região mediana

8b. Seno levemente marcado ou indistinto

Phymatodocis alternans

11a. Cloroplastídio estrelado

12a. Seno mediano levemente marcado

Hyalotheca dissiliens var. tatrica

12b. Seno mediano indistinto

13a. Parede celular lisa, levemente pontuada

13b. Parede celular com grânulos

Hyalotheca dissiliens var. dissiliens $f$. dissiliens.

11b. Cloroplastídio laminar.

Hyalotheca mucosa Groenblandia undulata var. undulata.

Tabela 3 - Freqüência das desmídias de hábito filamentoso presentes em oito amostras das 102 analisadas.

Table 3 - Frequency of filamentous desmids habit present in eight of the 102 analyzed samples.

\begin{tabular}{|c|c|c|c|c|c|c|c|c|}
\hline \multirow{4}{*}{ Táxons } & \multicolumn{8}{|c|}{ Amostras } \\
\hline & \multicolumn{6}{|c|}{ Chuva } & \multicolumn{2}{|c|}{ Seca } \\
\hline & \multicolumn{6}{|c|}{$\mathrm{N}^{0}$ de coletor } & \multicolumn{2}{|c|}{$\begin{array}{l}N^{0} \text { de } \\
\text { coletor }\end{array}$} \\
\hline & 805 & 808 & 825 & 827 & 829 & 834 & 1085 & 1095 \\
\hline Bambusina brebissonii Kützing ex. Kützing var. brebissonii. & & & & & & & & $\mathrm{X}$ \\
\hline Desmidium baileyi (Ralfs) Nordstedt var. baileyi f. baileyi. & $\mathrm{X}$ & $\mathrm{X}$ & & & & & & \\
\hline Desmidium bicristatosporum Grönblad & & & & & & & & $\mathrm{X}$ \\
\hline $\begin{array}{l}\text { Desmidium graciliceps (Nordstedt) Lagerheim } \\
\text { var. groenbladii C.E.M. Bicudo \& Samanez }\end{array}$ & & & & & & & & $\mathrm{X}$ \\
\hline Groenbladia undulata (Nordstedt) Förster var. undulata. & & & & $\mathrm{X}$ & $\mathrm{X}$ & & & $\mathrm{X}$ \\
\hline $\begin{array}{l}\text { Hyalotheca dissiliens (Smith) Brébisson } \\
\text { var. dissiliens f. dissiliens in Ralfs. }\end{array}$ & $\mathrm{X}$ & & $\mathrm{X}$ & $\mathrm{X}$ & & & & $\mathrm{X}$ \\
\hline $\begin{array}{l}\text { Hyalotheca dissiliens (Smith) Brébisson ex Ralfs } \\
\text { var. tatrica Raciborski. }\end{array}$ & & & & & & & & $\mathrm{X}$ \\
\hline Hyalotheca mucosa (Mertens) Ehrenberg ex. Ralfs. & & & & & & $\mathrm{X}$ & & $\mathrm{X}$ \\
\hline Onychonema laeve Nordstedt. var. laeve. & & & & & & $\mathrm{X}$ & & $\mathrm{X}$ \\
\hline Onychonema laeve Nordstedt. var. latum West \& West. & & & & & & $\mathrm{X}$ & & $\mathrm{X}$ \\
\hline Onychonema laeve Nordstedt. var. micracanthum Nordstedt. & & & & & & & & $\mathrm{X}$ \\
\hline Phymatodocys alternans Nordstedt. & & & & & & & & $\mathrm{X}$ \\
\hline Spondylosium ellipticum West \& West. & & & & & & & & $\mathrm{X}$ \\
\hline $\begin{array}{l}\text { Spondylosium panduriforme (Heimerl) Teil. } \\
\text { var. panduriforme f. panduriforme }\end{array}$ & & $\mathrm{X}$ & & & & & $\mathrm{X}$ & $\mathrm{X}$ \\
\hline $\begin{array}{l}\text { Spondylosium panduriforme (Heimerl) Teiling } \\
\text { var. limneticum (West \& West) Förster }\end{array}$ & $\mathrm{X}$ & $\mathrm{X}$ & & & & & $\mathrm{X}$ & $\mathrm{X}$ \\
\hline Spondylosium rectangulare (Wolle) West \& West. & & & & & & & & $\mathrm{X}$ \\
\hline $\begin{array}{l}\text { Teilingia excavata var. westii (Smith) Croasdale in Croasdale, } \\
\text { Bicudo \& Prescott }\end{array}$ & & & & & & & & $\mathrm{X}$ \\
\hline ' de coletor: número de coletor & & & & & & & & \\
\hline
\end{tabular}


Bambusina brebissonii Kützing ex. Kützing var. brebissonii. Species Algarum p. 188. 1849.

Fig. 2a-b

Células 2,1-2,2 vezes mais longas que largas; comprimento 43-44 $\mu \mathrm{m}$, largura $20 \mu \mathrm{m}$.

Material examinado: Formosa, Brejo entre os rios Jataí e dos Porcos, sentido Itiquira, 04.IX.2003, I.S. Nogueira et al. 1095 (UFG).

Distribuição geográfica no estado de Goiás: Caiapônia, Lagoa próxima ao rio Água Parada; Jataí, lagoa Sucuri, fazenda Bonsucesso; Porangatu, estrada Alvorada/Porangatu, lagoa marginal, lado direito; Paraúna, rio Ponte das Pedras (Dias \& Sophia 1994).

Desmidium baileyi (Ralfs) Nordstedt var. baileyi f. baileyi. Acta Universitatis Lundensis 16:4. 1880. Basônimo: Aptogonum baileyi Ralfs, British Desmidieae 208, pl. 35, fig. 1a-c. 1848. Fig. 4a

Células $1-1,2$ vezes mais longas que largas, comprimento com processo 20-23 $\mu \mathrm{m}$, comprimento sem processo $14-15 \mu \mathrm{m}$, largura17-22 $\mu \mathrm{m}$.

Material examinado: Iaciara, Brejo $2 \mathrm{~km}$ antes do rio São Mateus, 18.III.2003, I.S. Nogueira et al. 805, 808 (UFG).

Distribuição geográfica no estado de Goiás: Formoso de Goiás, Lagoa Grande (Dias \& Sophia 1994).

Desmidium bicristatosporum Grönblad. Acta Societatis Scientiarum Fennicae, Série B, 2(6): 34. 1945.

Fig. 2c-e

Filamento torcido, bainha de mucilagem presente, células $1-1,2$ vezes mais longas que largas, comprimento 36-41 $\mu \mathrm{m}$, largura 33-37 $\mu \mathrm{m}$, istmo $26-30 \mu \mathrm{m}$, constrição mediana marcada, semicélula piramidal-truncada, parede celular com 3-5 fileiras de grânulos tênues, cloroplastídio axial, zigósporo elíptico, parede lisa (zigósporo: comprimento 44,3 $\mu \mathrm{m}$ e largura $25,7 \mu \mathrm{m}$ ).

Material examinado: Formosa, Brejo entre os rios Jataí e dos Porcos, sentido Itiquira, 04.IX.2003, I.S. Nogueira et al. 1095 (UFG).

Distribuição geográfica no estado de Goiás: primeira citação para o estado de Goiás.

Desmidium graciliceps (Nordstedt) Lagerheim var. groenbladii C.E.M. Bicudo \& Samanez Bibliotheca Phycologica, 68: 39, fig. 11. 1984.

Fig. 2f,g

Filamento torcido, células 1,60-1,63 mais longas que largas; comprimento 53,9-56,1 $\mu \mathrm{m}$, largura 33,6-34,4 $\mu \mathrm{m}$, istmo $25,9 \mu \mathrm{m}$, células unidas pelo ápice, constrição mediana moderada, semicélula piramidal, margem apical retusa, parede celular lisa, presença de um pirenoide central em cada semicélula.

Material examinado: Formosa, Brejo entre os rios Jataí e dos Porcos, sentido Itiquira, 04.IX.2003, I.S. Nogueira et al. 1095 (UFG).

Distribuição geográfica no estado de Goiás: primeira citação para o estado de Goiás.

Groenbladia undulata (Nordstedt) Förster var. undulata. Nova Hedwigia 23(2/3): 578, pl. 26, fig. 10. 1972.

Basônimo: Hyalotheca undulata Nordstedt in Wittrock \& Nordstedt. Botaniska Notiser. 1879.

Fig. $4 \mathrm{~b}$

Células 1,5-2,0 vezes mais longas que largas; comprimento $15-20 \mu \mathrm{m}$; largura $13 \mu \mathrm{m}$; istmo 10-13 $\mu \mathrm{m}$. Os espécimes analisados apresentaram incrustação na parede celular em decorrência da deposição de ferro.

Material examinado: Formosa, Brejo entre os rios Jataí e dos Porcos, sentido Itiquira, 20.III.2003, I.S. Nogueira et al. 827 (UFG); Formosa, rio Itiquira, 20.III.2003, I.S. Nogueira et al. 829 (UFG); Formosa, Brejo entre os rios Jataí e dos Porcos, sentido Itiquira, 04.IX.2003, I.S. Nogueira et al. 1095 (UFG).

Distribuição geográfica no estado de Goiás: Caiapônia, Lagoa próxima ao rio Água Parada (Dias \& Sophia 1994).

Hyalotheca dissiliens (Smith) Brébisson var. dissiliens f. dissiliens in Ralfs. British Desmidieae 51, pl. 1, fig. 1. 1848.

Basônimo: Conferva dissiliens Smith. English Botany. 1812.

Fig. $2 \mathrm{~h}$

Células $1,2-1,4$ vezes mais longas que largas, comprimento 19-25 $\mu \mathrm{m}$, largura 16-17 $\mu \mathrm{m}$.

Material examinado: Iaciara, Brejo $2 \mathrm{~km}$ antes do rio São Mateus, 18.III.2003, I.S. Nogueira et al. 805 (UFG); Formosa, Rio Jataí, 20.III.2003, I.S. Nogueira et al. 825 (UFG); Formosa, Brejo entre os rios Jataí e dos Porcos, sentido Itiquira, 20.III.2003, I.S. Nogueira et al. 827 (UFG); Brejo entre os rios Jataí e dos Porcos, 04.IX.2003, I.S. Nogueira et al. 1095 (UFG).

Distribuição geográfica no estado de Goiás: Formoso, sentido: $21 \mathrm{~km}$ a leste (PresXcott 1957, como Hyalotheca dissiliens); Caiapônia, Lagoa próxima ao rio Água Parada; Jataí, lagoa Sucuri, fazenda Bom Sucesso; Paraúna, rio Ponte das Pedras (Dias \& Sophia 1994, como Hyalotheca dissiliens var. dissiliens f. dissiliens). Caldas Novas - Reservatório da Usina Hidrelétrica de Corumbá, próximo a foz do córrego Rochedo (Felisberto \& Rodrigues 2002). 


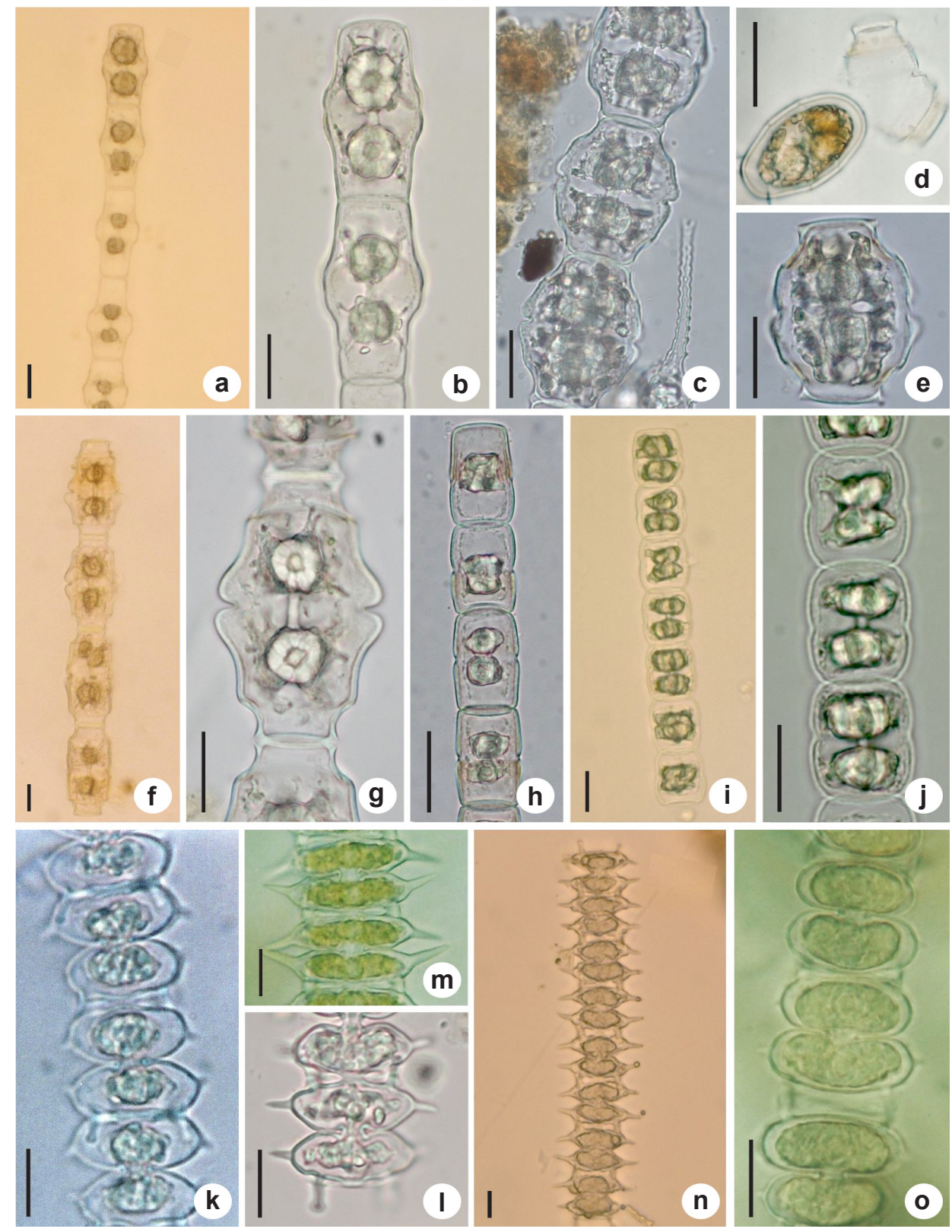

Figura 2 - a. Bambusina brebissonii Kützing ex. Kützing var. brebissonii. b. B. brebissonii Kützing ex. Kützing var. brebissonii (detalhe das células). c. Desmidium bicristatosporum Grönblad. d. D. bicristatosporum Grönblad(zigósporo). e. D. bicristatosporum Grönblad (detalhe da célula). f. Desmidium graciliceps (Nordstedt) Lagerheim var. groenbladii C.E.M. Bicudo e Samanez. g. D. graciliceps (Nordstedt) Lagerheim var. groenbladii C.E.M. Bicudo e Samanez (detalhe da célula). h. Hyalotheca dissiliens (Smith) Brébisson var. dissiliens f. dissiliens in Ralfs. i. Hyalotheca dissiliens (Smith) Brébisson ex Ralfs var. tatrica Raciborski.j. H. dissiliens (Smith) Brébisson ex Ralfs var. tatrica Raciborski (detalhe das células). k. Onychonema laeve Nordstedt. var. laeve. 1. O. laeve Nordstedt. var. laeve (detalhe dos processos). m. Onychonema laeve Nordstedt. var. latum West \& West (detalhe dos processos). n. O. laeve Nordstedt. var. latum West \& West. o. Onychonema laeve Nordstedt. var. micracanthum Nordstedt $($ Escala $=10 \mu \mathrm{m})$. Figure 2 - a. Bambusina brebissonii Kützing ex. Kützing var. brebissonii. b. B. brebissonii Kützing ex. Kützing var. brebissonii (detail of the cells). c. Desmidium bicristatosporum Grönblad. d. D. bicristatosporum Grönblad (zigospore). e. D. bicristatosporum Grönblad (detail of the cell). f. Desmidium graciliceps (Nordstedt) Lagerheim var. groenbladii C.E.M. Bicudoe Samanez. g. D. graciliceps (Nordstedt) Lagerheim var. groenbladii C.E.M. Bicudo e Samanez (detail of the cell). h. Hyalotheca dissiliens (Smith) Brébisson var. dissiliens f. dissiliens in Ralfs. i. Hyalotheca dissiliens (Smith) Brébisson ex Ralfs var. tatrica Raciborski. j. H. dissiliens (Smith) Brébisson ex Ralfs var. tatrica Raciborski (detail of the cells). k. Onychonema laeve Nordstedt var. laeve. 1. O. laeve Nordstedt var. laeve (detail of the process). m. Onychonema laeve Nordstedt. var. latum West \& West (detail of the process). $\mathrm{n}$. O. laeve Nordstedt. var. latum West \& West. o. Onychonema laeve Nordstedt. var. micracanthum Nordstedt (Scale bar $=10 \mu \mathrm{m})$. 
Hyalotheca dissiliens (Smith) Brébisson ex Ralfs var. tatrica Raciborski. Pamietnik Wydzial Akademie Umiejetnosci w Krakowie 10: 64, pl. 14, fig. 5. 1885.

Basônimo: Conferva dissiliens Smith. English Botany 35: pl. 2464. 1812.

Fig. 2i,j

Células $1-1,2$ vezes mais longas que largas, comprimento $22-25 \mu \mathrm{m}$, largura $18-22 \mu \mathrm{m}$; istmo $17-20 \mu \mathrm{m}$.

Material examinado: Formosa, Brejo entre os rios Jataí e dos Porcos, sentido Itiquira, 04.IX.2003, I.S. Nogueira et al. 1095 (UFG).

Distribuição geográfica no estado de Goiás: Jataí, Lagoa Sucuri, Fazenda Bonsucesso; Porangatu, estrada Alvorada/Porangatu, lagoa marginal, lado direito (Dias \& Sophia 1994).

Hyalotheca mucosa (Mertens) Ehrenberg ex. Ralfs. British Desmidieae 53, pl. 1, fig. 2. 1848.

Basônimo: Conferva mucosa Mertens in Dillwyn. British Confervae pl. B. $1809 . \quad$ Fig. 4c

Células 1,5 vezes mais longas que largas, comprimento $19 \mu \mathrm{m}$, largura $12 \mu \mathrm{m}$.

Material examinado: Flores de Goiás, alagado tipo várzea (Brejo) à 10,4 km antes da cidade de Flores, 26.III.2003, I.S. Nogueira et al. 834 (UFG); Formosa, Brejo entre os rios Jataí e dos Porcos, sentido Itiquira, 04.IX.2003, I.S. Nogueira et al. 1095 (UFG).

Distribuição geográfica no estado de Goiás: Formoso, sentido $20 \mathrm{~km}$ a leste (Prescott 1957, como Hyalotheca mucosa). Formoso de Goiás, Lagoa Grande; Porangatu, estrada Alvorada/Porangatu, lagoa marginal, lado direito (Dias \& Sophia 1994).

Onychonema laeve Nordstedt. var. laeve. Videnskabelige Meddlelser Dansk Naturhistorisk Forening v. 14-15, p. 206, Pl. 3, fig. 34, 1869.

Fig. 2k,1

Células 1,3-1,7 vezes mais largas que longas, comprimento com processos 27-32 $\mu \mathrm{m}$, comprimento sem processos 19-21 $\mu \mathrm{m}$, largura com espinho $42-46 \mu \mathrm{m}$, largura sem espinho $27-31 \mu \mathrm{m}$, istmo 4-6 $\mu \mathrm{m}$.

Material examinado: Flores de Goiás, alagado tipo várzea (Brejo) a 10,4 km antes da cidade de Flores, 26.III.2003, I.S. Nogueira et al. 834 (UFG); Formosa, Brejo entre os rios Jataí e dos Porcos, sentido Itiquira, 04.IX.2003, I.S. Nogueira et al. 1095 (UFG).

Distribuição geográfica no estado de Goiás: Jataí, lagoa Sucuri, fazenda Bom Sucesso; Porangatu, estrada Alvorada/Porangatu, lagoa marginal, lado direito (Dias \& Sophia 1994). Caldas Novas Reservatório da Usina Hidrelétrica de Corumbá, próximo à foz do córrego Rochedo (Felisberto \& Rodrigues 2002).
Onychonema laeve Nordstedt. var. latum West \& West. Transactions of the Linnean Society of London, Botany, II, 5(5): 232, pl. 12, fig. 18. 1896. Fig. 2m,n

Filamento pouco torcido, bainha de mucilagem ausente; células $1-1,03$ vezes mais longas que largas, comprimento com processo $25-27 \mu \mathrm{m}$, comprimento sem processo 16-21 $\mu \mathrm{m}$, largura com espinho 25-26 $\mu \mathrm{m}$, largura sem espinho 20-22 $\mu \mathrm{m}$, istmo 3-6 $\mu \mathrm{m}$; constrição mediana profunda; semicélula oblonga e em vista vertical mais estreita que a típica; margem lateral convergente prolongada em espinhos longos convergentes, margem apical côncava, dois processos equidistantes.

Material examinado: Flores de Goiás, alagado tipo várzea (Brejo) à 10,4 km antes da cidade de Flores, 26.III.2003, I.S. Nogueira et al. 834 (UFG); Formosa, Brejo entre os rios Jataí e dos Porcos, sentido Itiquira, 04.IX.2003, I.S. Nogueira et al. 1095 (UFG).

Distribuição geográfica no estado Goiás: primeira citação para o estado de Goiás.

Onychonema laeve Nordstedt. var. micracanthum Nordstedt. 1880. Acta Universitatis Lundensis 16, p. 3; West \& West 1896, Transactions of the Linnean Society of London, Botany, II, 5(5) 232, pl. 12:15-17.

Fig. 20

Filamento não torcido, bainha de mucilagem ausente, células $1-1,06$ vezes tão longas quanto largas, comprimento com processo 24-29 $\mu \mathrm{m}$; comprimento sem processo 19-20 $\mu \mathrm{m}$; largura com espinho 22-29 $\mu \mathrm{m}$; largura sem espinho 21-25 $\mu \mathrm{m}$; istmo 3-9 $\mu \mathrm{m}$; constrição mediana profunda, semicélula oblonga e em vista vertical forma fusiforme, margem lateral convexa prolongada em espinhos curtos e paralelos, margem apical côncava, dois processos longos equidistantes. Material examinado: Formosa, Brejo entre os rios Jataí e dos Porcos, sentido Itiquira, 04.IX.2003, I.S. Nogueira et al. 1095 (UFG).

Distribuição geográfica no estado Goiás: primeira citação para o estado de Goiás.

Phymatodocys alternans Nordstedt. Ofversigt af Kongliga Vetenskaps - Akademiens Forhandlingar 34(3): 19, pl. II: fig. 4. 1877.

Fig. 3a,b

Células tão longas quanto largas ou 1,3 vezes mais largas que longas, comprimento $18 \mu \mathrm{m}$, largura $24 \mu \mathrm{m}$, istmo $15 \mu \mathrm{m}$.

Material examinado: Formosa, Brejo entre os rios Jataí e dos Porcos, sentido Itiquira, 04.IX.2003, I.S. Nogueira et al. 1095 (UFG).

Distribuição geográfica no estado Goiás: Caiapônia, Lagoa próxima ao rio Água Parada; Formoso de Goiás, Lagoa Grande (Dias \& Sophia 1994). 

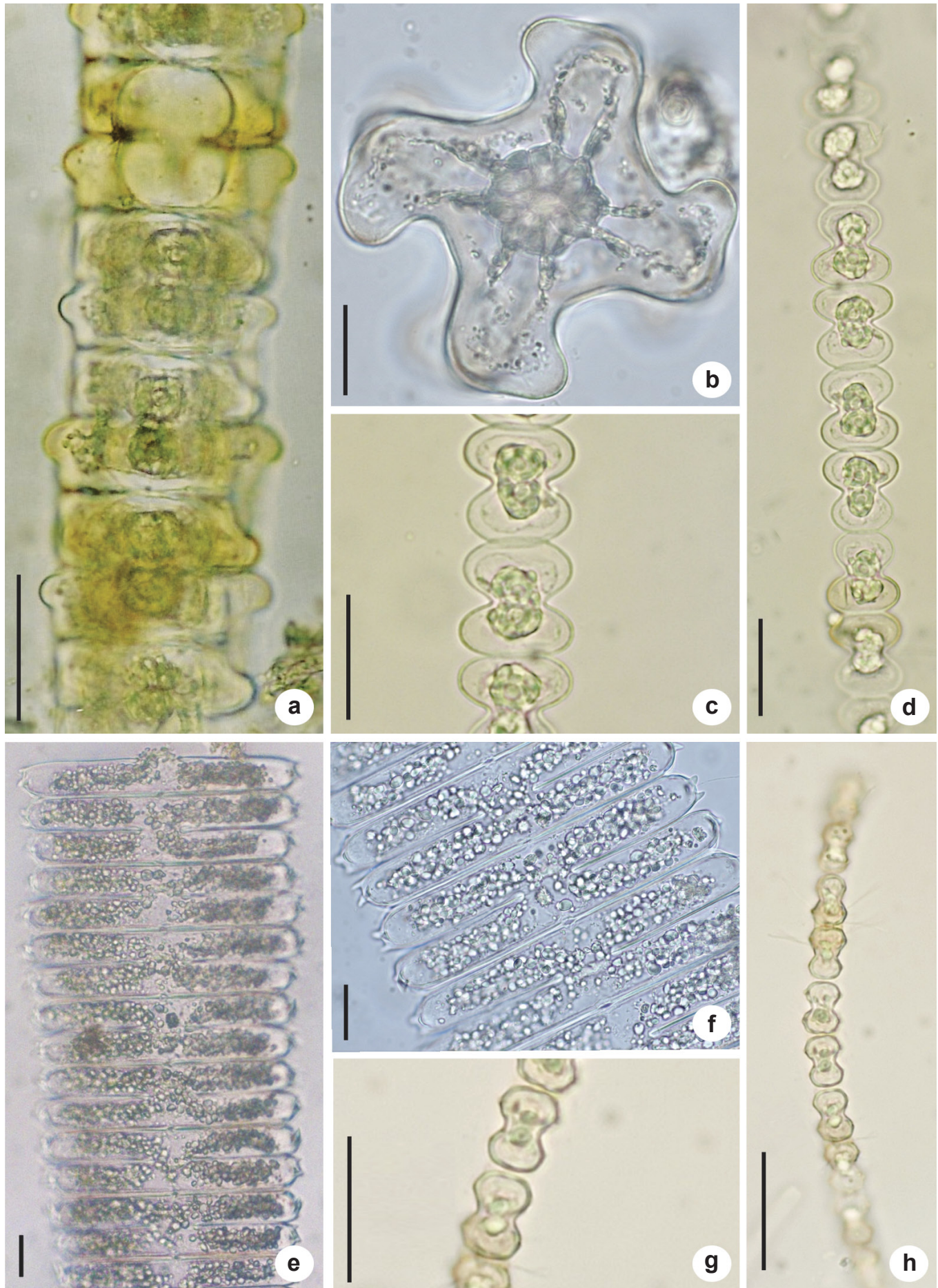

Figura 3 - a. Phymatodocys alternans Nordstedt. b. P. alternans Nordstedt (vista apical). c. Spondylosium ellipticum West \& West (detalhe da célula). d. S. ellipticum West \& West. e. Spondylosium rectangulare (Wolle) West \& West. f. S. rectangulare (Wolle) West \& West (detalhe dos dentes). g. Teilingia excavata var. westii (Smith) Croasdale in Croasdale, Bicudo \& Prescott (detalhe das células). h. Teilingia excavata var. westii (Smith) Croasdale in Croasdale, Bicudo \& Prescott (Escala $=10 \mu \mathrm{m})$. Figure 3 - a. Phymatodocys alternans Nordstedt. b. P. alternans Nordstedt (apical sight). c. Spondylosium ellipticum West \& West (detail of the cell). d. S. ellipticum West \& West. e. Spondylosium rectangulare (Wolle) West \& West. f. S. rectangulare (Wolle) West \& West (detail of the teeth). g. Teilingia excavata var. westii (Smith) Croasdale in Croasdale, Bicudo \& Prescott (detail of the cell). h. T. excavata var. westii (Smith) Croasdale in Croasdale, Bicudo \& Prescott (Scale bar $=10 \mu \mathrm{m})$. 
Spondylosium ellipticum West \& West. Transactions of the Royal Irish Academy: série B, 32: 43, pl. II: fig. 21. 1902.

Fig. 3c,d

Filamento levemente torcido, células 1,18 vezes mais longas que largas, comprimento $15 \mu \mathrm{m}$; largura $13 \mu \mathrm{m}$; istmo $6 \mu \mathrm{m}$; constrição mediana profunda, semicélula elíptica, margem lateral arredondada, margem apical convexa, parede celular lisa.

Material examinado: Formosa, Brejo entre os rios Jataí e dos Porcos, sentido Itiquira, 04.IX.2003, I.S. Nogueira et al. 1095 (UFG).

Distribuição geográfica no estado Goiás: primeira citação para o estado de Goiás.

Spondylosium panduriforme (Heimerl) Teil. var. panduriforme f. panduriforme. Svensk Botanisk Tidskrift. 51: 215. 1957.

Basiônimo: Cosmarium moniliforme f. panduriformis Heimerl. Verhandlungen zoologisch - botanischen Gesellschaft in Wien 41: 598, pl. V: fig. 11. 1891.

Fig. $4 \mathrm{e}$

Filamento levemente torcido, bainha de mucilagem ausente; células 1,8-1,9 vezes mais longas do que largas, comprimento $15-18 \mu \mathrm{m}$; largura

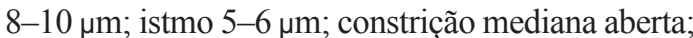
semicélula circular, margem lateral arredondada; margem apical com uma tênue elevação, truncada na parte mediana, parede celular lisa.

Material examinado: Iaciara, Brejo $2 \mathrm{~km}$ antes do rio São Mateus, 18.III.2003, I.S. Nogueira et al. 808 (UFG); São João da Aliança, Córrego Ribeirão, 03.IX.2003, I.S. Nogueira et al. 1085 (UFG); Formosa, Brejo entre os rios Jataí e dos Porcos, sentido Itiquira, 04.IX.2003, I.S. Nogueira et al. 1095 (UFG).

Distribuição geográfica no estado Goiás: primeira citação para o estado de Goiás.

Spondylosium panduriforme (Heimerl) Teiling var. limneticum (West \& West) Förster. Archiv für Hydrobiologie, Supplement, 63(4): 377. 1983.

Basônimo: Cosmarium moniliforme var. limneticum (West \& West). British Desmidiaceae III: 23, pl. LXVII: figs 6,7. 1908.

Fig. $4 d$

Células 2,3 vezes mais longas do que largas, comprimento 46-49 $\mu \mathrm{m}$, largura 20-21 $\mu \mathrm{m}$, istmo $8 \mu \mathrm{m}$.

Material examinado: Iaciara, Brejo $2 \mathrm{~km}$ antes do rio São Mateus, 18.III.2003, I.S. Nogueira et al. 805, 808 (UFG); São João da Aliança, Córrego Ribeirão, 03.IX.2003, I.S. Nogueira et al. 1085 (UFG); Formosa, Brejo entre os rios Jataí e dos Porcos, sentido Itiquira, 04.IX.2003, I.S. Nogueira et al. 1095 (UFG).

Distribuição geográfica no estado Goiás: Formoso de Goiás, Lagoa Grande (Dias \& Sophia 1994).
Spondylosium rectangulare (Wolle) West \& West. Transactions of the Linnean Society of London, Botany. 5: 231, 1896.

Basônimo: Sphaerozosma rectangulare Wolle. Desmids of the United States: 31, pl. XLIX: fig. 9. 1884.

Fig. $3 \mathrm{e}, \mathrm{f}$

Filamento não torcido, bainha de mucilagem ausente, células 3,8-4,1 vezes mais longas que largas, comprimento 27,9-29,6 $\mu \mathrm{m}$, largura 115,2-116,9 $\mu \mathrm{m}$, istmo $18,8 \mu \mathrm{m}$, constrição mediana profunda, semicélula oblongo-retangular, presença de dois dentes divergindo para o ângulo de cada margem lateral, um dente posicionado ao meio no interior da margem, parede celular lisa, presença de dois pirenoides em cada semicélula.
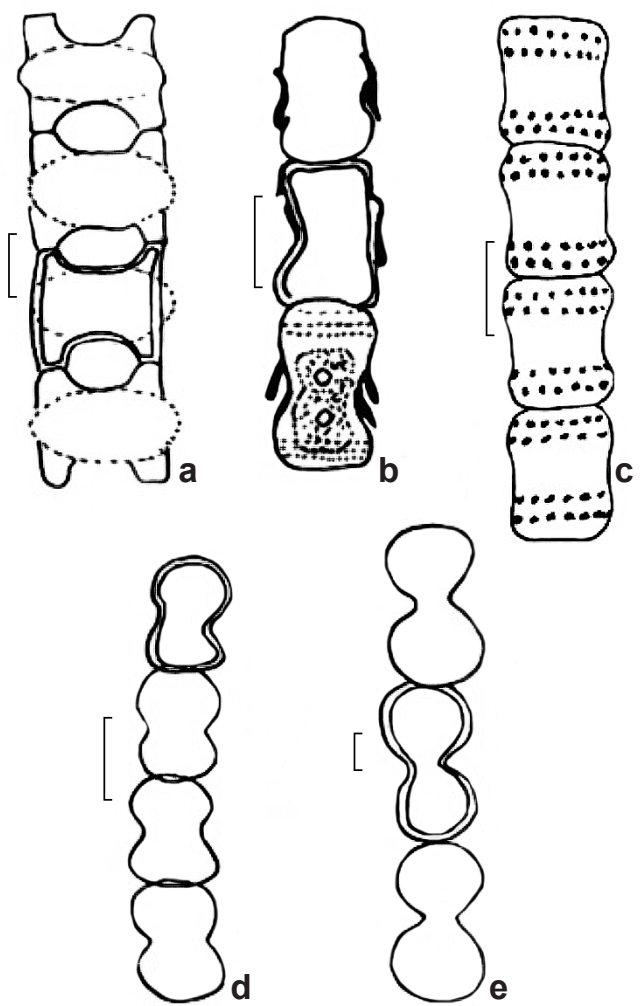

Figura 4 - a. Desmidium baileyi (Ralfs) Nordstedt var. baileyi f. baileyi. b. Groenbladia undulata (Nordstedt) Förster var. undulata. c. Hyalotheca mucosa (Mertens) Ehrenberg ex. Ralfs. d. Spondylosium panduriforme (Heimerl) Teiling var. limneticum (West \& West) Förster. e. Spondylosium panduriforme (Heimerl) Teil. var. panduriforme f. panduriforme $($ Escala $=10 \mu \mathrm{m})$.

Figure 4 - a. Desmidium baileyi (Ralfs) Nordstedt var. baileyi f. baileyi. b. Groenbladia undulata (Nordstedt) Förster var. undulata. c. Hyalotheca mucosa (Mertens) Ehrenberg ex. Ralfs. d. Spondylosium panduriforme (Heimerl) Teiling var. limneticum (West \& West) Förster. e. Spondylosium panduriforme (Heimerl) Teil. var. panduriforme $\mathrm{f}$. panduriforme $(\mathrm{Scale} \mathrm{bar}=10 \mu \mathrm{m})$. 
Neste estudo Spondylosium rectangulare apresentou dimensões (comprimento e largura) superiores ao que foi referenciado por West \& West (1896). No entanto, observa-se que a razão largura/ comprimento para esta espécie foi semelhante ao descrito por Grönblad (1945).

Material examinado: Formosa, Brejo entre os rios Jataí e dos Porcos, sentido Itiquira, 04.IX.2003, I.S. Nogueira et al. 1095 (UFG).

Distribuição geográfica no estado Goiás: primeira citação para o estado de Goiás.

Teilingia excavata var. westii (Smith) Croasdale in Croasdale, Bicudo \& Prescott. A Synopsis of North American Desmids 2(5): 8. 1983.

Basônimo: Sphaerozosma excavata var. westii Smith. Wisconsin Geological \& Natural History Survey, Bull. 57(2): 139, pl. 86: figs. 19 e 20. 1924.

Fig. 3g,h
Filamento não torcido, bainha de mucilagem presente, células 1,42 vezes mais longas que largas, comprimento $8,7-9,1 \mu \mathrm{m}$, largura $6,4 \mu \mathrm{m}$, istmo 3,3-3,4 $\mu \mathrm{m}$, constrição mediana ampla e rasa, semicélula trapezoidal, margem cônica-arredondada com 1-2 grânulos tênues, ápice com 2-4 grânulos. Material examinado: Formosa, Brejo entre os rios Jataí e dos Porcos, sentido Itiquira, 04.IX.2003, I.S. Nogueira et al. 1095 (UFG).

Distribuição geográfica no estado Goiás: primeira citação para o estado de Goiás.

O gênero com maior número de táxons foi Spondylosium (Spondylosium ellipticum, Spondylosium rectangulare, Spondylosium panduriforme var. limneticum e Spondylosium panduriforme var. panduriforme f. panduriforme). Na Tabela 4 é possível verificar a distribuição dos táxons nos diferentes ambientes estudados.

Tabela 4 - Demonstrativo da distribuição geográfica dos táxons registrados.

Table 4 - Demonstrative of the geographical distribution of taxa recorded.

\begin{tabular}{|c|c|c|}
\hline Município & Local & Táxons registrados \\
\hline Iaciara & $\begin{array}{l}\text { Brejo } 2 \mathrm{~km} \text { antes do rio São } \\
\text { Mateus - E3 }\end{array}$ & $\begin{array}{l}\text { Desmidium baileyi var. baileyi f. baileyi } \\
\text { Hyalotheca dissiliens var. dissiliens f. dissiliens } \\
\text { Spondylosium panduriforme var. panduriforme f. panduriforme } \\
\text { Spondylosium panduriforme var. limneticum }\end{array}$ \\
\hline Formosa & Rio Jataí - E11 & Hyalotheca dissiliens var. dissiliens f. dissiliens \\
\hline Formosa & $\begin{array}{l}\text { Brejo entre os rios Jataí e } \\
\text { dos Porcos - E12 }\end{array}$ & $\begin{array}{l}\text { Bambusina brebissonii var. brebissonii } \\
\text { Desmidium bicristatosporum } \\
\text { Desmidium graciliceps var. groenbladii } \\
\text { Groenbladia undulata var. undulata } \\
\text { Hyalotheca dissiliens var. dissiliens f. dissiliens } \\
\text { Hyalotheca dissiliens var. tatrica } \\
\text { Hyalotheca mucosa } \\
\text { Onychonema laeve var. laeve } \\
\text { Onychonema laeve var. latum } \\
\text { Onychonema laeve var. micracanthum } \\
\text { Phymatodocis alternans } \\
\text { Spondylosium ellipticum } \\
\text { Spondylosium panduriforme var. panduriforme f. panduriforme } \\
\text { Spondylosium panduriforme var. limneticum } \\
\text { Spondylosium rectangulare } \\
\text { Teilingia excavata var. westii }\end{array}$ \\
\hline Formosa & Rio Itiquira - E13 & Gröenbladia undulata var. undulata \\
\hline Flores de Goiás & $\begin{array}{l}\text { Alagado tipo } \\
\text { várzea (Brejo) - E19 }\end{array}$ & $\begin{array}{l}\text { Hyalotheca mucosa } \\
\text { Onychonema laeve var. laeve } \\
\text { Onychonema laeve var. latum }\end{array}$ \\
\hline $\begin{array}{l}\text { São João da } \\
\text { Aliança }\end{array}$ & Córrego Ribeirão - E24 & $\begin{array}{l}\text { Spondylosium panduriforme var. panduriforme f. panduriforme } \\
\text { Spondylosium panduriforme var. limneticum }\end{array}$ \\
\hline
\end{tabular}


O presente estudo foi realizado em cinco municípios da região do Vale e Serra do Paranã, em 31 estações de coleta com 102 amostras coletadas $(44,1 \%$ no período chuvoso; $55,9 \%$ na seca). As desmídias filamentosas foram registradas em apenas 9,7\% das amostras, porém em uma distribuição longitudinal ocorrendo em quatro municípios. O município de Formosa obteve o maior número de desmídias filamentosas (16 táxons), principalmente, devido ao maior número de amostras coletadas.

Apesar da diminuição do volume de águas nos mananciais estudados e até mesmo ausência de água (solo úmido) em algumas estações amostradas, observou-se que a seca foi o período com maior riqueza específica de desmídias de hábito filamentoso.

A região do Vale e Serra do Paranã têm sido consideradas uma das mais novas fronteiras agrícolas do estado de Goiás com a previsão de descaracterização dos recursos hídricos e consequentemente perda de espécies de algas que ainda não foram registradas para o estado de Goiás.

Bambusina brebissonii var. brebissonii, Desmidium bicristatosporum, Desmidium graciliceps var. groenbladii, Hyalotheca dissiliens var. tatrica, Onychonema laeve var. micracanthum, Phymatodocis alternans, Spondylosium ellipticum, Spondylosium rectangulare e Teilingia excavata var. westii ocorreram exclusivamente no período seco enquanto que Desmidium baileyi var. baileyi f. baileyi foi o único táxon restrito ao período de chuva (Tab. 5).

Este artigo constitui a primeira contribuição sobre o estudo de táxons de algas continentais para a região do vale e serra do Paranã, além de registrar oito novas citações para o estado de Goiás, ampliando o conhecimento da biodiversidade em território nacional.

Tabela 5 - Táxons ocorrentes nos diferentes períodos de amostragem: (1) chuva; (2) seca.

Table 5 - Taxa occurring in the different sampling periods: (1) rain; (2) dry.

\begin{tabular}{|c|c|}
\hline Táxons ocorrentes & Período de amostragem \\
\hline Bambusina brebissonii var. brebissonii & $(2)$ \\
\hline Desmidium baileyi var. baileyi f. bailey & (1) \\
\hline Desmidium bicristatosporum & $(2)$ \\
\hline Desmidium graciliceps var. groenbladii & $(2)$ \\
\hline Groenbladia undulata var. undulata & (1) $(2)$ \\
\hline Hyalotheca dissiliens var. dissiliens f. dissiliens & (1) $(2)$ \\
\hline Hyalotheca dissiliens var. tatrica & $(2)$ \\
\hline Hyalotheca mucosa & (1) $(2)$ \\
\hline Onychonema laeve var. laeve & (1) $(2)$ \\
\hline Onychonema laeve var. latum & (1) $(2)$ \\
\hline Onychonema laeve var. micracanthum & $(2)$ \\
\hline Phymatodocys alternans & $(2)$ \\
\hline Spondylosium ellipticum & $(2)$ \\
\hline Spondylosium panduriforme var. panduriforme f. panduriforme & (1) $(2)$ \\
\hline Spondylosium panduriforme var. limneticum & (1) $(2)$ \\
\hline Spondylosium rectangulare & (2) \\
\hline Teilingia excavata var. westii & (2) \\
\hline
\end{tabular}




\section{Agradecimentos}

As autoras agradecem ao Ministério do Meio Ambiente/PROBIO 2003 e ao CNPq, o fomento concedido.

\section{Referências}

Bicudo, C.E.M. \& Menezes, M. 2006. Gênero de algas de águas continentais do Brasil (Chave para identificação e descrição). RiMa Editora, São Carlos. 489 p.

Brandão, D. \& Kravchenko, A. 1997. A biota do Campus Samambaia: história, situação e perspectivas. SEGRAF-UFG, Goiânia. 157p.

Brasil. 2004. Segundo relatório nacional para a convenção sobre diversidade biológica. Ministério do Meio Ambiente/ Diretoria do Programa Nacional de Conservação da Biodiversidade - DCBio. MMA, Brasília. 347p.

Brasil. 2007. Biodiversidade do Cerrado e Pantanal: áreas e ações prioritárias para conservação/ Ministério do Meio Ambiente. MMA, Brasília. 540p.

Campos, I.F.P. \& Macedo-Saidah, F.F. 1990. Flórula da represa da escola de agronomia da Universidade Federal de Goiás, Goiânia, Goiás, Brasil. In: Anais do XXXVI Congresso Nacional de Botânica, Curitiba. IBAMA/SBB, Brasília. Pp. 839-857.

Crosdale, H.; Flint, E.A. \& Racine, M.M. 1994. Flora of New Zealand: Freshwater algae, chlorophyta desmids with ecological comments on their habitats: Volume III. Lincoln, Canterbury, New Zealand. $218 \mathrm{p}$.

Dias, I.C.A. \& Sophia, M.G. 1994. Desmidiaceae, Oedogoniaceae e Zygnemaceae. In: Campos, I.F.P.; Rizzo, J.A. \& Pereira, H.D. Vol. 3. Flora dos Estados de Goiás e Tocantins - Criptógamos, Goiânia. 56p.

Felisberto, S.A. \& Rodrigues, L. 2002. Desmidiales (exceto gênero Cosmarium) perifíticas no reservatório de Corumbá, Goiás, Brasil. Iheringia, Série Botânica 57: 75-97.

Förster, K. 1964. Desmidiaceen aus Brasilien, 2: Bahia, Goyas, Piauhy, und Nord. Brasilien. Hidrobiologia, Den Haag, 23: 321-505.

Grönblad, R. 1945. De algis brasiliensibus, praecipue Desmidiaceis, in regione fluminis Amazonas a Prof. August Ginzberger (Wien) anno 1927 collectis - Acta Societatis Scientiarum Fennicae, Tom. 2: 1-43.
Hoek, C. van den; Mann, D.G. \& Jahns, H.M. 1995, Algae an introduction to phycology. Cambridge University Press, Cambridge. 623p.

Lenzenweger, R. 1997. Desmidiaceenflora von Österreich. Teil 2. Bibliotheca Phycologica 102: 1-216.

Martins-Silva, M.J.; Engel, D.W.; Rocha, F.M. \& Araújo, J. 2008. Imaturos de Trichoptera na bacia do Rio Paranã, GO, com novos registros de gênero. Neotropical Entomology 37: 735-738.

Myers, N.; Mittermeier, R.A.; Mittermeier, C.G.; Fonseca, G.A.B \& Kent, J. 2000. Biodiversity hotspots for conservation priorities. Nature 403: 853-858.

Oliveira, I.B.; Bicudo, C.E.M. \& Moura, C.W.N. 2010. Novas ocorrências de desmídias filamentosas (Desmidiaceae, Zygnematophyceae) para o estado da Bahia, Brasil. Acta Botanica Brasilica 24: $1017-$ 1026.

Oliveira, M.T.; Rocha, O. \& Peret, A.C. 2011. Structure of phytoplankton community in the Cachoeira Dourada reservoir (GO/MG), Brazil. Brazilian Journal of Biology 71: 587-600.

Prescott, G.W. 1957. The Machris Brazilian expedition, botany: Chlorophyta, Euglenophyta. Los Angeles County Museum Contributions in Science 11: 1-29.

Prescott, G.W.; Croasdale, H.T. \& Bicudo, C.E.M. 1982. A synopsis of North American Desmids, Part II, Desmidiaceae: Placodermae, Section 4. University of Nebrasca Press, Lincoln and London. 700p.

Reviers, B. 2003. Biologie et phylogénie des algues. Tome 2. Belin, Paris. 255p.

Scariot, A.; Freitas, S.R.; Neto, E.M.; Nascimento, M.T.; Oliveira, L.C.; Sanaiotti, T.; Sevilha, A.C. \& Villela, D.M. 2003. Efeitos da fragmentação sobre a biodiversidade: vegetação e flora. In: Rambaldi, D.M. \& Oliveira, D.A.S. Fragmentação de ecossistemas: causas, efeitos sobre a biodiversidade e recomendações de políticas públicas. MMA/SBF, Brasília. 510p.

Silva, C.A.; Train, S. \& Rodrigues, L.C. 2001. Estrutura e dinâmica da comunidade fitoplactônica a jusante e montante do reservatório de Corumbá, Caldas Novas, Estado de Goiás, Brasil. Acta Scientiarum 23: 283-290.

West, W. \& West, G.S. 1896. One some North American Desmidieae. Transactions of the Linnean Society of London, Botany 5: 229-274. 